\title{
CHEMOTHERAPY IN MALIGNANT DISEASE
}

\section{Introduction}

\author{
D. A. G. Galton, M.A., M.B., B.Chir. \\ Chester Beatty Research Institute, London, S.W.3
}

IN the last 15 years chemotherapy has come to be recognized as playing an essential part in the palliative management of a few types of malignant disease. The natural and synthetic sex hormones and their derivatives are now in general use in the routine treatment of mammary and prostatic carcinoma; systemic chemotherapy by means of the so-called antimetabolites is the main form of treatment in the acute leukæmias; and the biological alkylating agents are equal in importance to radiotherapy in the treatment of the chronic leukæmias, some malignant lymphomata, and generalized Hodgkin's disease. The place of systemic chemotherapy in these very restricted fields is generally acknowledged, but there is less agreement on its role in other and commoner forms of malignant disease. The value of the alkylating agents in the treatment of ovarian adenocarcinoma is becoming more widely known (Coonrad and Rundles, 1959), but it is perhaps too early to define the precise indications for using them. It is unfortunate that many of the conditions in which chemotherapy is of most value are rarities, such as chorioncarcinoma, which may respond to the antimetabolites methotrexate and mercaptopurine (Buckle, 1959; Hertz, Bergenstal, Lipsett,

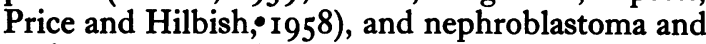
perhaps other embryonal tumours in which suitable combinations of surgery, radiotherapy and cytotoxic antibiotics like actinomycin D and mitomycin $\mathrm{C}$ are reported to give far better results than were obtained before chemotherapy was introduced (Farber, D'Angio, Evans and Mitus, 1960). The common forms of malignant disease, particularly the gastro-intestinal carcinomata, are almost all resistant to chemotherapy, while carcinoma of the bronchus and breast are significantly influenced by cytotoxic drugs only in doses close to or within the lethal range.

\section{The Biological Alkylating Agents}

A majority of the biological alkylating agents that have been submitted to clinical trial belong to one of three chemical classes: the chloroethylamines or the ' nitrogen mustards'; the ethyleneimines; and the dimesyloxyalkanes, of which busulphan (Myleran) is the best known example. $\vec{\circ}$ These substances are all toxic to every type of proliferating cell. Malignant cells appear to beo affected by them because they are proliferating cells, and not because of the special properties associated with their malignancy.

The alkylating agents differ amongst themselvesi in their physico-chemical properties, which in turnos are responsible for their effects on living tissues..$\omega$ The cells play no active part in concentrating ${ }^{\circ}$ most of these drugs within themselves, but recently attempts have been made to link the chemical ${ }^{-}$ properties of compounds of this type more closely $\subseteq$ with biological processes. The rationale of these $\mathrm{D}$ attempts has varied. Thus the incorporation $\mathrm{gf}_{\bullet} \overrightarrow{0}$ sugars, as in mannomustine (Vargha, 1955), wo요요 intended to improve the transport of the substanse across cell membranes, while the incorporation of amino-acids as in phenylalanine nitrogen mustard (melphalan, sarcolysine) (Bergel and Stock, 1954;

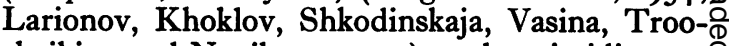
sheikina and Novikova, 1955), and pyrimidines as in dopan (Larionov and Platonova, 1955) and $\overrightarrow{\bar{O}}$ uracil nitrogen mustard (Shanbrom, Miller, Opfell and Haar, 1960) was intended to increase the uptake of the drugs at sites of active protein and nucleoprotein synthesis, where it was even흑 conceivable that the drugs might function as:amino-acid or pyrimidine antagonists. Finally, attempts have been made to ensure that the destruction of the cell requires the active intervention of $\stackrel{\circ}{\beta}$ biochemical processes. These compounds have been made by combining the active alkylating group with a 'carrier' residue that renders it $\frac{}{2}$ inactive. Intracellular enzymes would be necessary to split off the inactivating group, thus liberating $\mathcal{N}$ the cytotoxic moiety within the cell. Cyclophos- $N$ phamide (Endoxan) is an example of this type of N compound.

The selective uptake of these compounds would 2 depend on differences in the distribution among the tissues of the enzyme necessary for splitting $\stackrel{\mathscr{D}}{+}$ the molecule. The weakness of this approach is that there is no satisfactory evidence that malignant ${ }_{0}^{\circ}$ tissues contain any enzymes in higher concentra- $\mathbb{D}$ tions than normal tissues. It is, however, possible, $\stackrel{?}{\mathbb{P}}$ 
though unlikely, that a compound might be prepared requiring for its activation the agency of an enzyme not present in bone marrow cells. The major disadvantage of all the presently available alkylating agents is their toxicity to the hæmopoietic cells; the synthesis of a compound relatively inactive against these cells would be a real advance, for none of the newer agents yet shows significant selectivity in its clinical effects. All function as typical nitrogen mustards, with only relatively minor quantitative differences from the original compound mustine. Some of these differences are of considerable clinical importance, comparable with those between rapidly-acting and slowly-acting barbiturates.

\section{The Comparative Assessment of Chemo- therapeutic Drugs}

The comparative assessment of the value of a number of similar drugs is extremely difficult. Apparent differences may be due only to differences in the method of administration or in the relative size of the doses employed. The response to one compound may be long delayed, and by changing to a second compound too hurriedly the benefit eventually conferred may be erroneously attributed to the second drug. A drug may acquire a reputation of being especially useful in the treatment of a particular condition simply because it was, by chance, the first to have been tested on a large scale. Similar results might have been obtained had a different compound been chosen. Chronic lymphocytic leukæmia is a good example of a disease in which many different compounds have been claimed to be effective. Each of the following alkylating agents is in routine use at the present time at different centres: nitrogen mustard N-oxide (Nitromin), chlorambucil, mannomustine (Degranol), cyclophosphamide (Endoxan), 2naphthylamine nitrogen mustard $\left(\mathbf{R}_{4} 8\right)$, triethylenemelamine (TEM), triethylenethiophosphoramide (thio-TEPA, TSPA), bisethyleneiminobenzoquinone ( $E_{39}$ ), trisethyleneiminobenzoquinone (Trenimon). The similarity of the published results described for each of these compounds suggests that in chronic lymphocytic leukæmia the experience of the clinician is more important than the particular merits of the compounds. Each investigator becomes familiar with the effects of one or two drugs and is less likely to obtain equally good results with the drugs he has used less often.

Busulphan (Myleran) is widely believed to be the drug of choice for the treatment of chronic granulocytic leukæmia (Dameshek and Gunz, I958; Hayhoe, I960), but equally good results have been claimed for many other alkylating agents, especially triethylenemelamine (Bethell, 1958) and trisethyleneiminobenzoquinone (Linke, 1960), as well as for the purine antagonist, 6-mercaptopurine (Fountain, 1956). However, a carefully controlled co-operative trial (Rundles, Grizzle, Bell, Corley, Frommeyer, Greenberg, Huguley, Watson James, Jones, Larsen, Loeb, Leone, Palmer, Riser and Wilson, 1959), in which busulphan and chlorambucil were compared in their ability to induce remissions in chronic granulocytic leukæmia, demonstrated beyond doubt that busulphan was more effective than chlorambucil in chronic granulocytic leukæmia and less effective in chronic lymphocytic leukæmia.

The most important differences between the various alkylating agents from the clinical point of view are: first, that the more rapidly-acting drugs, such as mustine, are often more useful for bringing about rapid effects, for example, in the initial treatment of generalized Hodgkin's disease, while the more slowly-acting drugs, such as chlorambucil or cyclophosphamide, are more suitable for maintenance therapy; and, secondly, that patients who fail to respond or cease to respond to one agent may respond to another.

\section{The Use of High Doses of Alkylating Agents}

For many years it has been recognized that the risk of damaging the bone marrow was the limiting factor in the dosage of cytotoxic drugs, especially the alkylating agents. It seemed likely that tumours that occasionally regressed slightly for short periods after treatment with conventional doses might respond better if larger doses could be administered. This view was supported by the necropsy findings in patients who failed to survive the administration of large doses of cytotoxic drugs, in which the tumour masses appeared to be largely necrotic. The administration of one or two large doses of alkylating agents, for example, triethylenemelamine, has been reported to relieve distressing symptoms for many months in patients suffering from advanced bronchial carcinoma (Jack, Doyle and Palewalla, 1960; Jack, 1960; Dr. M. Farquharson, private communication). During the period of pancytopenia, which may last for several weeks, the patient's life is threatened by the risks of massive hæmorrhage or of bacterial or fungal infections. If he survives, helped by transfusions of fresh blood, and by the administration of antibiotics, he has a chance of obtaining a worthwhile remission. Clearly, treatment on these lines cannot be undertaken without the most careful consideration of the circumstances in each case, and since it involves grave risks the patient is entitled to be told something of its possible consequences. Dameshek attempted to reduce the effects of supralethal doses of nitrogen mustard in treating patients with advanced Hodgkin's disease and lymphosarcoma by aspirating a quantity of bone 
marrow before the drug was administered and returning it a few hours later, when the drug would have lost most of its activity (McFarland, Granville and Dameshek, 1959). Subsequent experience with this method has not been encouraging, since the disease usually recurred in a few weeks (W. Dameshek, personal communication), suggesting that the dose of a cytotoxic drug required to destroy the tumour is likely to be even higher than was believed. How much higher has become apparent since cytotoxic drugs have been administered by the local perfusion of tumourbearing regions.

\section{Regional Perfusion of Cytotoxic Drugs}

This method entails the isolation of the region as completely as possible from the rest of the body and maintaining its circulation by means of a mechanical pump and an oxygenating device. Large doses of a cytotoxic drug may be thus largely confined to the perfusion system without damaging the vulnerable tissues of the rest of the body. The method was first used by Creech and his colleagues (Creech, Krementz, Ryan, Reemtsma and Winblank, 1959). The most successful results have been obtained in the treatment of malignant melanoma confined to the distal parts of the upper or lower limbs. The perfusion of other regions has always been associated with the leakage of the drug into the general circulation.

It is important to note that the doses of cytotoxic drugs cannot be increased indefinitely when administered by regional perfusion, even when leakage into the general circulation is negligible. This is because at high dose levels tissues other than the bone marrow are damaged, especially vascular endothelium, nerve, muscle and skin (private communication, Mr. C. I. Cooling and Mr. M. D. Staunton). However, doses proportionally many times greater than would be possible by systemic administration can be given. In spite of this, the tumours always appear to recur, though sometimes only after months or even years, indicating that some tumour cells survive very high concentrations of cytotoxic drugs. It is therefore clear that in the case of systemic administration even the highest doses that could be tolerated would be hopelessly inadequate, even for tumours like malignant melanoma that occasionally show some response to conventional doses.

\section{Prophylactic Chemotherapy}

It is now known that malignant cells escape into the venous blood draining tumours (Fisher and Turnbull, 1955; Kuper, Bignall, and Luckock, 1961). It has also been claimed that the number of malignant cells escaping from tumours into the veins increases during operative manipulations. In the hope of reducing the number of free cells, cytotoxic drugs have therefore been ad- $\frac{\Phi}{\circ}$ ministered at the time of radical surgery (Economou, Mrazek, McDonald, Slaughter and Cole, $\stackrel{\vec{\Rightarrow}}{\vec{\Rightarrow}}$ I958), but it is too early to know whether this $\stackrel{\vec{S}}{+}$ method will be of value in preventing or delaying the appearance of metastases.

\section{Antimetabolites}

The use of folic-acid antagonists in the treatment of acute leukæmia in childhood has been known since 1948 (Farber, Diamond, Mercer, Sylvester and Wolff, 1948), but their application to the treatment of chorioncarcinoma is more recent (Bethell, 1958; Buckle, r959; Hertz et al., 1958). Many purines and pyrimidine analogues have been prepared, of which 6-mercaptopurine is $\omega$ the best known. The fluorinated pyrimidines 5 - i fluorouracil and its deoxyriboside (fluoro-deoxy- of uridine) have undergone extensive clinical trials in many forms of malignant disease. They are highly toxic to the intestinal epithelium as well as to the bone marrow and remissions have been disappointingly infrequent and have occurred only when doses large enough to cause toxic effects have been administered. The metabolic processes blocked by the antimetabolites so far prepare 8 appear to be as important to normal proliferating. cells as they are to malignant cells. As in the cast of the alkylating agents, there seems little evidence that the antimetabolites act in a qualitatively selective manner on malignant cells.

\section{Conclusion}

It is difficult to foresee the lines along which chemotherapy is likely to develop as long as we remain ignorant of the qualitative differences between normal and malignant cells. There seem to be many ways in which cells become malignant, and there are, as yet, no means of knowing whether a final common path is involved. Much experimental work on malignant disease, and especially experimental chemotherapy, necessarily proceeds on the assumption that all malignant growths share some common abnormality. If this difference from normal cells were known, a more rational approach to chemotherapy would be possible.

A major difficulty is that none of the available biological tests for potential chemotherapeutic agents provides a very reliable guide to the probable effects of the compounds on human malignant disease. The antimetabolites also show great differences in their toxicity for different animal species. Elion and her colleagues (Elion, Callahan, Hitchings and Rundles, 1960) have shown that different species vary in their capacity to detoxicate mercaptopurine and related compounds. 
Clinical trials have therefore to be carried out on an empirical basis, and it is not possible to infer from the results of experimental tests that one type of human malignant disease is more likely to respond than another. The use of fragments of human tumours, grown in tissue cultures or in the cheek pouches of hamsters, might seem to afford better material for testing chemotherapeutic agents than the transplanted or spontaneous animal tumours. The conditions under which the human tissues are grown and exposed to the drugs are, however, highly artificial and a great deal of critical work will have to be done if misleading conclusions are not to be drawn from this type of work. It is probable that a compound with exceptional tumour-inhibitory properties would be readily recognized by any of the commonly used methods of testing.

\section{REFERENCES}

Arnold, H., Bourseaux, F., and Brock, N. (1958): Chemotherapeutic Action of a Cyclic Nitrogen Mustard Phosphamide Ester (B 51 8-Asta) in Experimental Tumours of the Rat, Nature (Lond.), r8r, 931.

Bagshawe, K. D., and Brooks, W. D. W. (1959): Subacute Pulmonary Hypertension Due to Chorionepithelioma, Lancet, $\mathrm{i}, 6_{53}$.

Bergel, F., and Stock, J. A. (1954): Cyto-active Amino-acid and Peptide Derivatives. Part I: Substituted Phenylalanine, f. chem. Soc., 2409.

Bethell, F. H. (1958): Myleran and Triethylene Melamine in the Treatment of Chronic Granulocytic Leukemia, Ann. N.Y. Acad. Sci., 68, 996.

Buckle, A. E. R. (1959): Methotrexate in Treatment of Metastasizing Chorioncarcinoma, Brit. med. Y., ii, r2 ro.

Coonrad, E. V., and Rundles, R. W. (1959): Mustard Chemotherapy in Ovarian Carcinoma, Ann. intern. Med., 50, 1449.

Creech, O., Krementz, E. T., Ryan, R. F., Reemtsma, K., and Winblad, J. N. (1959): Experiences with Isolationperfusion Technics in the Treatment of Cancer, Ann. Surg., 149, 627.

Dameshex, W., and Gunz, F. (1958): 'Leukemia', p. 387. New York and London: Grune \& Stratton.

Economou, S. G., Mrazek, R., McDonald, G., Slaughter, D., and Cole, W. H. (1958): The Intraperitoneal Use of Nitrogen Mustard at the Time of Operation for Cancer, Ann. N.Y.Acad. Sci., 68, 1097.

Elion, G. B., Callahan, S. W., Hitchings, G. H., and Rundles, R. W. (1960): Relationship Between Drug Metabolism and Antitumor Effects of Thiopurines in Mouse and Man, Proc. 8th Int. Congr. of Hamatol., Paper 273.

Farber, S., D'Angio, G., Evans, A., and Mitus, A. (1960): Clinical Studies of Actinomycin D with Special Reference to Wilm's Tumor in Children, Ann. N.Y. Acad. Sci., 89, 42 r.

- Diamond, L. K., Mercer, R. D., Sylvester, R. F., and Wolff, J. A. (1948): Temporary Remissions in Acute Leukemia in Children Produced by Folic Acid Antagonist 4-Aminopteroylglutamic Acid (Aminopterin), New Engl. F. Med., 238, 787 .

Fisher, D. R., and Turnbull, R. B. (1955): The Cytologic Demonstration and Significance of Tumor Cells in the Mesenteric Venous Blood in Patients with Colorectal Carcinoma, Surg. Gynec. Obstet., 100, 102.

Fountain, J. R. (1956): Treatment cf Chronic Myeloid Leukaemia with Mercaptopurine, Brit. med. J., 2, r 345.

Hayhoe, F. G. J. (1960): 'Leukaemia', p. 250. London: J. \& A. Churchill.

Hertz, R., Bergenstal, D. M., LipsetT, M. B., Price, E. B., Hilbish, T. F. (1958): Chemotherapy of Chorioncarcinoma and Related Trophoblastic Tumors in Women, Y. Amer. med. Assoc., 168, 845.

JaCk, G. D., Doyle, L., and Palewalla, M. M. (1960): Tretamine in the Treatment of Inoperable Lung Cancer, Lancet, i, 206.

Kuper, S. W. A., Bignall, J. R., and Eveline Luckock (196r): A Quantitative Method for Studying Tumour Cells in Blood, Lancet, i, 852 .

- (1960): Tretamine in the Treatment of Inoperable Lung Cancer, Ibid., i, 335.

Larionov, L. F., and Platonova, T. N. (1955): Antitumorigenic Action of 4-Methyl-5-di(2-Chlorethyl)aminouracil (Dopan), Vop. Onkol., 3, 36.

- Khoklov, A. S., Shkodinskaja, E. N., Vasina, O. S., Troosheikina, V. I., and Novikova, M. A. (ig55): Studies on the Anti-tumour Activity of $p$-di-(2-Chloroethyl)aminophenylalanine (Sarcolysine), Lancet, i, 169.

Linke, A. (1960): Therapy of Hemoblastosis, Proc. 8th Int. Congr. of Hamatol., Paper 232.

McFarland, W., Granville, N. B., and Dameshek, W. (1959): Autologous Bone Marrow Infusion as an Adjunct in Therapy of Malignant Disease, Blood, 14, 503.

Rundles, R. W., Grizzle, J., Bell, W. N., Corley, C. C., Frommeyer, W. B., Greenberg, B. G., Huguley, C. M., Watson James, G., Jones, R., Larsen, W. E., Loeb, V., Leone, L. A., Palmer, J. G., Riser, W. H., and Wilson S. J. (1959): Comparison of Chlorambucil and Myleran in Chronic Lymphocytic and Granulocytic Leukema, Amer. F. Med., 27, 424 .

Sha.rbrom, E., Miller, S., Opfell, R., and HAar, H. (I960): Therapy of Leukemia and Lymphomas with Uracilmustard, a New Oral Alkylating Agent, Proc. 8th Int. Congr. of Hamatol., Paper 280.

Shay, H., and Sun, D. C. H. (1958): Experimental and Clinical Experience with Thio-TEPA in Leukemia and Inoperable Cancer, Ann. N.Y. Acad. Sci., 68, 1046.

UltmanN, J. E., Hyman, G. A., and Gellhorn, A. (1958): Chlorambucil and Triethylene Thiophosphoramide in the Treatment of Neoplastic Disease, Ibid., 68, 1007.

VARGHA, L. (1955): Uber neue Zuckerderivate mit Zytostatischer Wirksamkeit, Naturwissenschaften, $42,582$. 